\title{
Structure Equation Analysis on Customer Satisfaction of Public Transport: An Empirical Study in Klang Valley Malaysia
}

\author{
Lye Mei Yi, Tan Siew Wan ,Kavitha Haldorai , Abdul Rahman, Rasheedul Haque, , Pan Haibin, Yang Shengnan \\ Faculty of Business and Accounting, Linton University College, \\ Mantin, Negeri Sembilan Malaysia
}

\begin{abstract}
The purpose of this research is to determine the factors influencing international tourist satisfaction on the public rail services in Klang Valley, Malaysia. This paper provides important contribution to the Malaysian economy due to the growing number of international tourist in recent years. A mixed methodology approach via the use of phenomenological interviews and self-administered questionnaire were use. Structure equation modelling (SEM) revealed three key dimensions of public rail service attributes which is comfort, accessibility, responsiveness and safety. The result indicated that there is significant relationship between comfort, safety and accessibility. Transportation authorities can use these findings as a guide to enhance the quality of life of public rail service users in the future.
\end{abstract}

Keywords: Chinese Tourist, Public Transport, Customer Satisfaction, Ktm, Comfort

\section{Introduction}

A recent survey in Malaysia indicated that there has been phenomenal growth in tourists visiting Malaysia over the last few years. In 2016, Malaysia received 26.7 million tourists with receipts amounting to RM82.1bil, an $18.8 \%$ increase compared with RM69.1bil in 2015. Despite these encouraging figures, the population of Chinese tourist decreased from 2.12 million in 2016 to $1,523,846$ in 2017. The possible reason for the drop in China tourist are due to the dissatisfaction in the rail transportation service in the city, therefore the service quality of the rail transport need to be highlighted. (Mytourism data, 2017)

Malaysia rail public transport service connect the surban localities of Kuala Lumpur region to the city centre. It play an important role as one of the major transport providers in the city and has contributed to the traffic on congested road networks. For tourist who do not have access to a private vehicle, the rail public transport provides access and mobility.

In order to improve the rail service quality for international tourist, there is a need to better understand the elements of the tourist rail experience that are up most important to the current and potential tourist Investigating consumers' perceptions of rail service quality (RSQ) will help towards that end. One of the important concerns when obtaining consumers' evaluations is to identify dimensions which are most crucial to consumers in assessing rail service quality. A number of existing studies on rail service quality have tried to determine the dimensions used to define customers' perception of service quality, and to build models that the rail service experience (Haron, Nasir \& Mohammad, 2016; Govender 2014; Chua et al.2016). Among these studies, there are some formal researches on rail service quality that focuses on developing measures for the evaluation of websites. In support, Murambi and Bwisa (2014) state that travel time, punctuality, clear information, good staff behaviour, assured board security significantly the overall satisfac- tion of public transport shuttle transport. Haron, Nasir, \& Mohamad (2016) also focused on service performance indicator: environment, physical facilities accessibility, reliability provided by KTM (Keretapi Tanah Melayu) and LRT (Light Rail Transit) in the Klang Valley. Ismail, Hafezi, Nor \& Ambak (2012) study revealed that service quality is related to overall customer preference and satisfaction with Malaysian public transportation network and found out that respondents have shown to rate their satisfaction level as lower than preference levels. This indicates that the quality of Malaysian public transportation network is under the travelers' expectation of the service from frequency, comfortable travel experience, security on board and travel time.

Ilhaamie (2010) study on 300 respondents from Malaysian public organizations emphasized on quality, expectation and perception to improve the public confidence towards Malaysian public rail transport. Moreover, the authorities to take some actions and measures in order to increase the present level of service quality especially.

There are several purposes of this research. Firstly, to identify dimensions of RSQ of e-auction sites that are crucial to the Chinese Tourists. Secondly, developing a scale to empirically assess these dimensions. Thirdly, developing theoretically-related constructs, like satisfactions and likelihood of future visit to assess the nomological validity of the scale.

After this, a relevant literature review relevant to Chinese tourist' perspective of rail service quality was carried out. This is followed by a quantitative method to develop a five-factor RSQ scale, making use of a questionnaire. Finally, a discussion of theoretical and managerial implications was carried out.

\section{Literature review}

\subsection{Rail Service Quality}


In recent years, many studies have been conducted to reveal the factors that can reduce private transport use and increase the number of ridership of the public transport in the city area. Among the many factors examined, much of the literature had emphasized on the importance of service quality factors in encouraging people to switch to the public transport. Service quality has been dominating the construct towards public transport studies.

A number of existing studies on rail service quality have tries to determine the elements that define customers' perception of traffic service quality, and to establish the models that outline customers' rail service experience (Abdul Aziz Abdullah, Talip (2013); Zakaria, Hussin et al. (2010); Kamaruddin, Osman \& Pei et al.(2012); Suria Haron, Nasir et al. (2016); Liu Yao, Fadilah Sail et al.(2014), Bachok, Osman et al.(2013); have further stated that there are essential research studies which need to be conducted on rail services so as to better understand the dimensions of rail service quality.

Abdullah and Talip (2013) emplaced case study on Malaysian public transportation reveal that reliability, safety, speed, comfort and punctuality are the dimensions of service quality which the organization believes that these will be the most influential factors affected the perceived quality. This study also clarifies and thus, contributes to the key dimensions of service quality that influence the perceived quality service, in a specific means of public transportation.

Zakaria, Husin, Abdul, (2010) a study in Lembah Bujang, Kedah reveal that the result indicates there are positive correlations between service quality, tangible, reliability and responsiveness of service quality dimensions. The most service quality dimensions influence the service quality is that tangible dimension which is focuses on cleanliness/comfortable of physical facilities.

Kamaruddin, Osman, Pei (2012) A modeling study on public transport services in Klang Valley, Malaysia indicated that the customers' expectations on public transport service were based generally on the account of safety. Findings also indicate that positive significant relationships between customer satisfactions, environment and loyalty, as well as positive significant relationship between environmental concern and loyalty.

A pioneering study on electrical rail transportation (Haron, Nasir Mohamed, 2016) revealed that the service quality indicators for KTM had been classified into five factors such a environment, physical facilities, accessibility, reliability, safety and security, reliability, responsiveness and physical facilities. While, for LRT few other factors such as environment, physical facilities, accessibility, reliability, safety and security are the highlights.

Liu Yao, Sail, Darun, Ismail (2014) Further, public transportation study on 150passengers in the east Malaysia verify that the five services quality dimensions positively contribute to customer satisfaction reliability, assurance, tangibles assurance and empathy are the key factors influence the tourist perception of service quality.

That the majority of the respondents performance perceived KTM service to be below the levels that the users had expected, especially the non-adherence to published schedule and travel times, frequency or headways, capacity, the physical conditions of the rail coaches and the information on delays. Bachok, Osman, Khalid, and Ibrahim (2013) in contrast, results of commuters' perception on rail based public transport services have shown.

\section{Research Framework}

A theoretical framework has been developed to explain the interrelationship among the variables that contribute to the problem stated. This framework is formulated based on the customer's satisfaction on public transportation services to define relationship among variables. Three (4) independent variable (IV) and one (1) dependent variable (DV) have been chosen in this study. Dependent variable is a customer's satisfaction; meanwhile independent variables are exception, perceived service quality and disconfirmation. The theoretical framework can be projected in figure 1 .

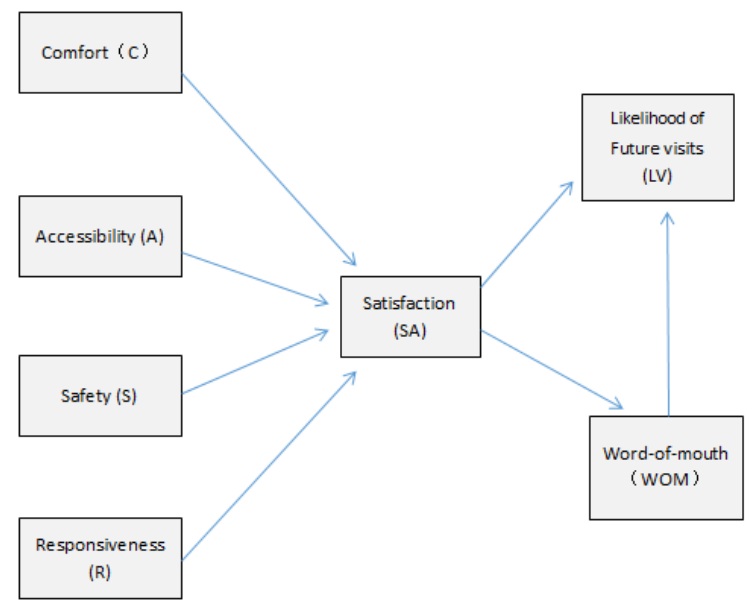

Figure1: Conceptual Framework Customer Satisfaction

In view of the above research context, we strongly believe that the proposed hypothesized model is novel as it attempts to explain the effect of customer expectations and in turn, its subsequent effect on satisfaction, loyalty and environment. The hypothesized model is depicted in figure 1 .

The hypotheses model is as follows:

H1: Satisfaction mediates the relationship between comfort and likelihood of future visits.

H2: Satisfaction mediates the relationship between accessibility and likelihood of future visits.

H3: Satisfaction mediates the relationship between safety and likelihood of future visits.

H4: Satisfaction mediates the relationship between responsiveness and likelihood of future visits.

H5: There is a relationship between satisfaction and word-ofmouth.

H6: There is a relationship between word-of-mouth and likelihood of future visits.

H7: Word-of-mouth mediates the relationship between satisfaction and likelihood of future visits.

\section{Research methodology}

\subsection{Overview}

The data was collected using online survey, the questionnaire was distributed online, 150 peoples responded to the survey. Data was also collected manually from survey Monkey. An instrument was developed, for each of variable in conceptual framework. The construct comfort, accessibility have 4 indicators, safety, respon- 
siveness have 3 indictors. These construct were adopted from Nasarudin et al., (2014). The construct satisfaction has 4 indicators while construct word of mouth and likelihood of future visits have 3 indicators. These construct were adopted from Trocchia et al., (2002). All the items they measure 5 points Likert scale - from strongly agree to strong disagree. The data will be analyzed via Structural equation modelling using PLS software.

\subsection{Data Collection Process}

In the initial phase of this research, semi-structured interviews were used to collect data (Thompson et al., 1989). Three primary investigators and 5 postgraduates' students trained in phenomenological interviewing techniques (Patton, 1990). Study 1 participants comprised 2 women and 3 men, ranging in age from 24 to 26. Educational levels ranged from undergraduate to postgraduate. Interviews ranged from one half-hour to two hours in duration, with most lasting approximately one hour. The focus of the interviews was to tap consumers' feelings and perceptions regarding public rail transportation. This was accomplished by asking informants to describe their experiences with public rail transportation that allowed them to make their importance -performance rating. Interview guides were used to ensure that pertinent issues were covered (McCracken, 1988). All interviews were taperecorded and transcribed.

Three primary investigators independently coded data from each interview, and analyzed the interview transcripts using hermeneutic logic. Such logic involves an iterative process of reading, synthesizing, and categorizing the transcript data (Thompson et al., 1989). Such a process, and subsequent discussions between the three investigators, resulted in five themes pertaining to Malaysia public transportation service quality. These five themes were labeled convenience, safety, accessibility and information.

\subsection{Analysis and results}

The summary of demographic characteristics of the respondents indicates equal contribution among male and female with more than half from age category of $20-29$. More than half of the respondents have a minimum qualification of degree. Most of them are single from China.

The hypotheses were tested using SmartPLS.

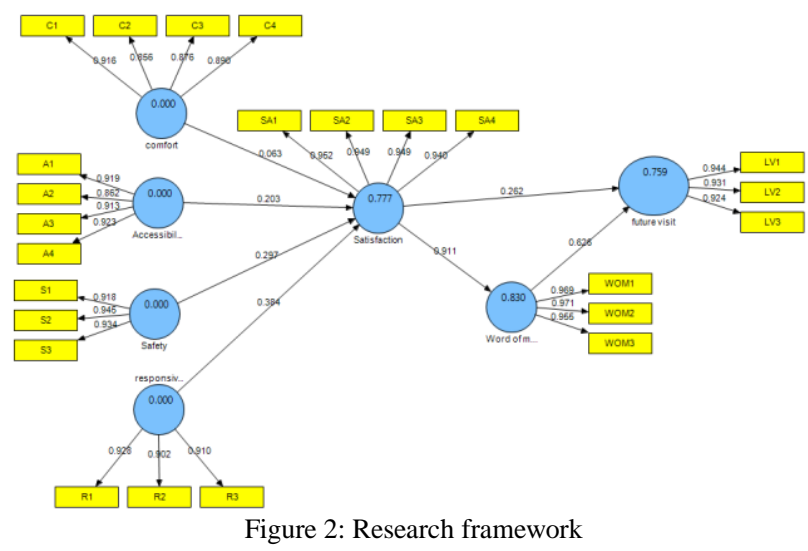

In Table 1, satisfaction acts as a mediating variable and mediates the relationship between comfort, accessibilities, safety and responsiveness and future visit and word of mouth.

\subsection{Assessment of Measurement Model}

For the items, convergent validity was accessed through the loadings, composite reliability and average variance extracted (Hair et al., 2010). All the item above 0.6 which is the recommendation value (Chin et al, 1997). From Table 1 it is observed that the indi- cator reliability exceeded the minimum acceptable level of 0.4 (Hulland, 1999). The composite reliability exceeded the recommended value of 0.7 (Hair et al., 2010) and the average variance extracted exceeded 0.5 (Hair et al., 2010). Hence, the convergent validity was achieved as shown in Table 2 determine the discriminant validity, the Fronell-Larcker criterion was used. It can be observed from Table 2 that the square root of the average variance extracted is largest than off-diagonal values, indicating discriminant validity is achieved (Fornell and Larcker, 1981)

The bootstrapping analysis showed that all indirect effects are significant for safety. Also as indicated by Preacher and Hayes (2008), the indirect effects 95\% Boot CI did not straddle a zero in between indicating there is mediation, thus, we can conclude that satisfaction mediated the relationship between safety and likelihood of future visit. Similarly word of mouth mediated the relationship between satisfaction and likelihood of future visit. (Table $3)$. However, the indirect effects were not effective for comfort, accessibility, responsiveness. Since the indirect effects 95\% Boot CI straddled a zero, it can be concluded that satisfaction did not mediate the relationship comfort, accessibility, responsiveness and likelihood of future visit.

\section{Discussion}

\subsection{Theoretical Implications}

From a theoretical point of view, the study offers and tests a conceptual model of Rail services. The study reveals the determinants of Rail service quality and links them with customer satisfaction. The findings of the study are expected to provide an insight to regulatory bides, practitioners and academicians in understanding the theoretical framework.

The study intends to build on recent theoretical work aimed at extending the boundaries of how rail services is defined and researched. The research contributes to rail services literature by empirically testing several hypotheses and by suggesting possibilities for future research.

Previous studies on international tourist perception of rail service quality have been rather limited. This study has identified key dimensions which influence international tourist perception of Malaysian rail services. Some key dimensions are unique to the Malaysian public transportation environment and mark a departure from the traditional rail service quality models which has dominated the literature for years.

\subsection{Managerial Implications}

The main objective of this study is to examine how the modified SERVQUAL model is going to affect the public land transportation users" behavioral purchase intentions. The modified SERVQUAL model can be used by the government agencies and public land transport operators as an indicator in maintaining and improving the service quality of public land transportation to encourage the public to use them. Among the four independent variables, safety has the most significant effect on behavioral purchase intentions in the public land transportations service and thus government agencies and public land transport operators should pay greatest attention in providing a safer public land transportation service. Lady Coach is a typical good approach by the service operator to take care of the commuter safety. Further safety measure could further enhance this dimension such as installation of CCTV or any other preventive measure, this is further enhance the confident to the commuter. The public land transport operators and the Land Public Transport Commission (SPAD) should conduct periodic inspection of the condition of public land transport vehicles in order to ensure that they are roadworthy. Besides that, the Royal Malaysian Police should increase patrols at the station 
to reduce the unlawful acts (i.e. vandalism on public transport and snatch thefts at the station)

The second most significant independent variable that influences the customer satisfaction the public land transportations service is responsiveness. The public land transport companies should provide training regularly to ensure their operating staffs are equipped with the relevant communication skills, knowledge and information in handling requests of the users and providing service efficiently which will lead to a better performance. As the terminal are moving towards automation, clear information shall provide to the commuter for easy reference such as clear signage with multi lingual to cater for the needs of foreign tourist main Chinese for China tourist which are the majority tourist in Malaysia. The operator shall ensure the ticketing machines are functioning effectively to avoid congestion and smooth operation flow in the terminal.

According to the result of this study, comfort is the last independent variable that has significant impacts on the behavioral purchase intentions in the public land transportations service. Public land transport operators should increase the numbers of handholds to avoid standing passengers from falling down during their ride. Besides that, SPAD should ensure that the public land transport operators have reserved seats near to the entrance and exit doors for elderly, disabled people and pregnant women by providing them a more accessible, safer and comfortable ride. One of the feedback receive from the study stated that some coach are crowded in the train, to overcome this, the operator may consider to increase the route to ease the crowd or the operator can consider to increase the number of coach during peak hour to ease the crowd. Commuter feedback that the train is shaking during the traveling, the commuter raise their most concern of in-comfort while traveling with the shaking coach.

Accessibility is one of the vital roles in commuter preference, the operator shall increase the connecting routes for a wider access to various locations in the city. With this, the commuter may have more choice in reaching their destination, the commuter will opt to travel with the rail transport at all time. The current situation is whereby the commuter need to check the access route prior to travel to reach their expected destination as some part of the city are not reachable by the rail transport. On top of that, the accessibility to the terminal shall be improved to attract the number of commuter in the train by increasing the bus transport connecting the terminal with the nearby residential housing estate. Malaysia rail transport are operated by different operator, the central planning shall ensure the convenient access among the interchange for the convenient of the commuter.

\subsection{Limitations and Future Research Directions}

This research is limited its sampling to Chinese tourists only. Besides China, other countries in Middle East and Europe, have a large number of public transport. By conducting research from different nations, some other nationalities opinions, insights and perspectives can be obtained and contribute to a more in-depth literature on the rail services.

An evident limitation of this study is the use of a convenience sampling. Although there are indeed numerous advantages of using this technique; namely the ease of finding respondents; there are also certain drawbacks. Due to the convenience sampling, the results of this study cannot be generalized. Boundaries are also one of the limitations.

As the research is mainly focused on Chinese, the results might not be accurate as the results of the research are based on the taste and preference of the tourists from China. For the purpose of future studies, the researchers can study more dimensions which are related to the rail service quality. In this research, there were only four dimensions, which are comfort, safety, accessibility, respon- siveness. Other key service dimensions such as price, information etc. should be explored further.

\section{Reference}

[1] Abdullah, A. and Talip, R. (2013) 'RapidKL Bus Service in City Center, Kuala Lumpur, Malaysia: An Epitome of Good Service'? International Journal of Academic Research in Business and Social Science, 3(4), pp. 333-349.

[2] Bachok, S et al. (2013) 'Commuters' Perceptions on Rail Based Public Transport Services: A Case Study of KTM Komuter in Kuala Lumpur City, Malaysia', Journal of the Malaysian Institute of Planners, XI(2013), pp. 97-124.

[3] Berhan, E., Beshah, B. and Kitaw, D. (2013) 'Performance Analysis on Public Bus Transport of the City of Addis Ababa', International Journal of Computer Information System and Industrial Management Applications, (5), pp. 722-728.

[4] Borhan, $\mathrm{N}$ et al. (2014) 'Predicting the Use of Public Transportation: A Case Study from Putrajaya, Malaysia', The Scientific World Journal, pp. 1-9.

[5] Cheng, H et al. (2010) 'The Service Quality Analysis of Public Transportation System using PZB Model - Dynamic Bus Information System', The Institute of Electrical and Electronics Engineers. Available at: http://ieeexplore.ieee.org/document/5668302/?reload=true (Accessed: $2^{\text {nd }}$ December 2017).

[6] Chin, W.W., Gopal, A. and Salisbury, W.D. (1997) 'Advancing the theory of adaptive structuration: The development of a scale to measure faithfulness of appropriation'. Information Systems Research, 8(4), pp. 342-367.

[7] Fen, S et al. (2016) 'Service Quality on Behavioural Purchase Intentions in the Public Land Transportations Service in Kuala Lumpur, Malaysia', Universiti Tunku Abdul Rahman, pp 1-87. Available at: http://eprints.utar.edu.my/2021/ (Accessed: 2 ${ }^{\text {nd }}$ December 2017).

[8] Fornell, C. and Larcker, D. F. (1981) 'Evaluating Structural Equation Models with Unobservable Variables and Measurement Error'. Journal of Marketing Research, 18(1), pp. 39-50.

[9] Hair, J.F et al. (2010) Multivariate Data Analysis. Prentice-Hall, Upper Saddle River, NJ.

[10] Haron. S., Nasir. B. and Mohamad S. 'Rail Transport Service Performance Indicators in Klang Valley', International Conference on Advanced Science, Engineering And Technology, pp. 1-6 Available

https://www.researchgate.net/publication/309549943_Rail_transpor $\mathrm{t} \_$service_performance_indicators_in_Klang_Valley (Accessed: $2^{\text {nd }}$ December 2017)

[11] Hulland, J. (1999) 'Use of partial least squares (PLS) in strategic management research: a review of four recent studies'. Strategic Management Journal, 20, pp. 195-224.

[12] IIhaamie. A. Service Quality in Malaysia Public Service: Some Findings, International Journal of Trade, Economics and Finance, 1(1), pp. 40-45.

[13] Ismail, R. et al. (2012) Passengers Preferences and Satisfaction of Public Transport in Malaysia, Australia Journal of Basic and Applied Sciences, 6(8), pp. 410-416.

[14] Janda, S., Trocchia, J. and Gwinner, P. (2002) Consumer perceptions of Internet retail service quality, International Journal of Service Industry Management, 13(5), pp 412-431.

[15] Kamaruddin, R., Osman, I. and Pei. C. (2012), Public Transport Services in Klang Valley: Customer Expectations and Its Relationship Using SEM, 36, pp. 431-438. Available at: http://www.sciencedirect.com/science/article/pii/S18770428120051 49 (Accessed: $2^{\text {nd }}$ December 2017).

[16] Murambi, N. and Bwisa, M. (2014) Service Quality and Customer Satisfaction in Public Transport Sector of Kenya: A Survey of Shuttle Travelers in Kitale Terminus, International Journal of Academic Research in Business and Social Science, 4(9), pp. 402-412.

[17] Muthupandian, S. and Vijayakumar, C. Measurement of Passengers Service Quality in Public Transportation: Seroquel Analysis, The Institute of Cost and Works Accountants of India, pp 1-24. Available at: https:// mpra.ub.uni-muenchen.de/38584 (Accessed on 2 Dec 2017)

[18] Noor, M., Nasarudin N. and Foo J (2014) Determinants of Customer Satisfaction of Service Quality: City bus service in Kota Kinabalu, Malaysia, 153, pp. 595-605. Available at: 
http://www.sciencedirect.com/science/article/pii/S18770428140553 47 (Accessed on 2 Dec 2017).

[19] Preacher K.J \& Hayes A F. (2008) Asympotic \& resampling strategies for assessing and comparing indirect effects in multiple mediator models. Behavior Research Methods,40(b),879-891

[20] Preacher, K.J. and Hayes, A.F. (2008) 'Asymptotic and resampling strategies for assessing and comparing indirect effects in multiple mediator models', Behavior Research Methods, 40(3), pp. 879-891.

[21] Rajeswari, V. and Kumari, S. (2014) Satisfaction and Service Quality in Indian Railways - A study on Passenger Perspective, IOSR Journal of Economics and Finance, 4(1), pp 58-66.

[22] Vanhanen, K., Kurri, J., Quality Factors in Public Transport, pp 1-7, Available at: http://transportation.org.il/en/node/3017 (Accessed on 2 Dec 2017).

[23] Verma, M., et al, (2013), Urban Bus Transport Service Quality and Sustainable Development: Understanding the GAPS, pp. 1-16. Available

https://www.researchgate.net/publication/263314835_Measuring_s ervice_quality_in_urban_bus_transport_A_modified_SERVQUAL approach (Accessed on 2 Dec 2017).

[24] Wijaya, D. (2009) 'Study of Service Quality in the Public Bus Transport: Customer Complaint Handling and Service Standards Design', Karlstads Universitets, pp 1-64.

[25] Yao, L. et al. (2014) Service Quality and Customer Satisfaction: Rapid Kuantan in Kuantan Route, Malaysia, International Conference on Social Sciences and Humanities, pp. 976-982.

[26] Zakaria, Z et al. (2010), Service Quality of Malaysian Public Transports: A Case Study in Malaysia, 6(2), pp 84-92. Available online:

http://www.cscanada.net/index.php/ccc/article/view/j.ccc.19236700 20100602.010/992 (Accessed on 2 Dec 2017). 